\title{
The impact of abusing return policies: A newsvendor model with opportunistic consumers
}

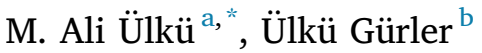 \\ ${ }^{\text {a }}$ Rowe School of Business, Dalhousie University, Halifax, NS, B3H4R2, Canada \\ ${ }^{\mathrm{b}}$ Faculty of Business Administration, and Department of Industrial Engineering, Bilkent University, Bilkent, 06800, Ankara, Turkey
}

\section{A R T I C L E I N F O}

\section{Keywords:}

Inventory management

Consumer behavior

Product returns

Fraudulent proclivity

Uncertain demand

Return policy

\begin{abstract}
A B S T R A C T
Consumers may return a product for a variety of reasons, such as the product having the wrong color or size, having poor functionality, being damaged during shipment, or simply prompting regret for an impulsive purchase. Retailers generally provide lenient return policies not only because they may signal high quality but also because they act as risk relievers for consumers' purchasing decision processes. However, increasing product returns have become particularly challenging for the efficient management of inventory. As such, at the crux of a holistic inventory model lies the understanding of consumer return behavior. In this study, we introduce a variant of the classical single-period inventory (newsvendor) model with returns, in which heterogeneous consumers decide, based on their post-purchase valuation of the product, whether to return the product after using it. From the perspective of the retailer, such deliberate returns may abuse the return policy, which in turn may exacerbate reverse logistics and environmental costs. To that end, we incorporate demand uncertainty and consumer valuation uncertainty by explicitly gauging return probabilities and differentiated salvage values into a newsvendor model. We derive analytical results for the profit-maximizing order quantity for a single-period product that comes with a retailer return policy and exclusively identify the impact of return type as abused or normal. Also offered are closed-form optimal solutions in the cases where market demand is exponentially or uniformly distributed. Structural and numerical results lend managerial insight into how optimal ordering amount, profit, return rates and salvage values change with the price, return window, and hassle cost of returning the product.
\end{abstract}

\section{Introduction}

On February 9, 2018, L.L.Bean Executive Chairman Shawn O. Gorman posted the following note on the company's Facebook account: “... Our commitment to customer service has earned us your trust and respect, as has our guarantee, which ensures that we stand behind everything we sell. Increasingly, a small, but growing number of customers has been interpreting our guarantee well beyond its original intent. Some view it as a lifetime product replacement program, expecting refunds for heavily worn products used over many years. Others seek refunds for products that have been purchased through third parties, such as at yard sales. Based on these experiences, we have updated our policy. Customers will have one year after purchasing an item to return it, accompanied by proof of purchase. After one year, we will work with our customers to reach a fair solution if a product is defective in any way ..."

One of the most generous in the retail industry, L.L.Bean's touted $100 \%$ satisfaction guaranteed return policy has been abused by consumers, forcing management to be slightly less forgiving by now imposing a one-year limit on most returns to reduce growing abuse and fraud (Hsu, 2018). Consumer returns are on the rise, and companies are probing their assumptions about consumer satisfaction and return behavior. Over the past five years, L.L.Bean, a giant outdoor recreational company based in the US, has lost $\$ 250$ million on returned items that cannot be salvaged in the secondary market or donated to charity but instead are simply destined for landfills. Because of increased return abuse and fraud, L.L.Bean has had to revisit its return policy.

When consumers are not satisfied, they expect to be able to return purchased goods. Not surprisingly, as the market grows, product returns become an important factor in retail operations. According to Appriss Retail (2017), about $10 \%$ of total sales in the US (more than $\$ 350$ billion loss in sales - a number close to the estimated 2017 federal budget deficit) were returned. Squeezed between the pressure of fierce competition for market share and increased expectations on the part of consumers, nearly all established retailers offer return policies (Davis et al., 1998).

\footnotetext{
* Corresponding author.

E-mail addresses: ulku@dal.ca (M.A. Ülkü), ulku@bilkent.edu.tr (Ü. Gürler).
} 
However, retail return policies (RRPs) themselves may bring challenges to retailers. RRPs affect not only how retailers determine accurate pricing and control inventory levels but also how they implement an efficient returns management system. In addition, the wide variety of return policies for industries and products increases the challenge. For competitive reasons, retailers such as L.L.Bean have offered very lenient return policies, sometimes with lifetime return windows. Although Wood (2001) reports that generous return policies signal high quality, particularly for remote purchases, Li et al. (2014) suggest that the majority of product returns are linked to consumer behavioral-related issues rather than quality functional problems of the product. Referred to as "false-failure returns" by Ferguson et al. (2006), such return behaviors may be the result of a consumer finding the product not suitable or easy enough to use or simply regretting an impulsive purchase. Moreover, those returns may be due to opportunistic consumers who take advantage of lenient return policies by purchasing items with the intent of using and returning them within the return window. Therefore, these types of returns by opportunistic consumers who abuse the return policies require a new analytical model that can integrate the probability of a mismatch of the product (functional failure) with the probability of abusing the return policy (false failure), as examined in this paper. As noted by Ketzenberg and Zuidwijk (2009, p.345), "Not only are lenient policies costly to operate, they are also open to consumer abuse. Indeed, the possibility of consumers abusing return policies is an important consideration that limits their use." Returning a camcorder after a wedding or returning a party dress after a prom are examples of opportunistic consumers abusing an RRP (Wood, 2001). According to a recent survey, approximately two out of every three customers are likely to return a product in their lifetime with the firm (Petersen and Kumar, 2015). Mostard and Teunter (2006) report that return rates on fashion items are approximately $35-40 \%$.

Motivated by the fact that most returns are related to behavior, that most returns are on perishable goods (e.g., fashion goods) and that ordering quantity must explicitly include returned orders for reselling or salvage, we develop a variant of the classical newsvendor problem (NVP) by incorporating an explicit return-rate term; we call our model newsvendor with opportunistic consumers (NVOC).

It may be possible for retailers to safeguard themselves from some of the effects of these returns through specific inventory controls. Although numerous studies on product returns and inventory management exist in the literature, to the best of our knowledge, research is lacking on explicitly linking opportunistic consumer behavior and retailers' optimal order quantity. For efficient inventory management, more sophisticated analytic models are needed. The ability to quantify the impact of falsefailure returns on ordering amounts may enable retailers to diagnose issues and devise inventory-related countermeasures (such as tracking product inventory and consumer purchase behavior) to mitigate the negative consequences to business; herein lies the basic motivation of our current research. We thus ask:

How can consumers' return behavior be integrated into a retailer's single-period inventory model? For a product that is highly prone to be abused by opportunistic consumers, what will be the profit-maximizing order quantity set by a retailer? How do the key parameters such as price and return window impact opportunistic consumer behavior?

The layout of this paper is as follows. Next, we give a brief review of the related literature. In Section 3, we develop and solve to optimality for a retailer the profit-maximizing single-period inventory problem in which both demand and consumer valuation uncertainties exist. In our NVOC model, we gauge through our modeling the consumer's postpurchase (return or keep) decision-making process and propose a method to quantify the probability that consumer will return the product (abused or normal). Next, in Section 4, we provide structural results for the optimal solutions. In Section 5, for the case of uniform and exponential demand, we derive closed-form solutions for the optimal expected order quantity and profit, and we conduct a sensitivity analysis to gain further insights into the problem. Section 6 offers closing thoughts and venues for future research.

\section{Literature review}

Consumers return products to retailers for a variety of reasons: the delivered product may be the wrong one (e.g., wrong size or color); the product might have turned out to be different than advertised (e.g., erroneous information); the product might have arrived damaged (e.g., improper handling during shipment or poor quality); or the consumer might simply have changed his or her mind after the purchase.

Terminology pertinent to consumers' return behavior is emerging. Although the majority of these returns are legitimate (e.g., wrong color delivered), some returns are associated with fraudulent or opportunistic proclivity. A "fraudulent return" is an illegitimate product return, such as seeking a refund on a used, consumer-damaged, or even a stolen product (Harris, 2008). Notably, another term under fraudulent returns is "opportunistic consumer returns" (e.g., Ya et al., 2014), which considers returns of used, non-defective merchandise. Alternatively, King and Dennis (2003) coin the term "deshopping" to identify the consumer behavior of purchasing a product with no intention of keeping it. Hjort and Lantz (2012) use the term "(r)e-tail borrowing," while Shang et al. (2017) use the term "wardrobing" to describe the behavior of consumers with fraudulent proclivity; such consumers opportunistically use the return option for short-term consumption instead of simply resolving fit uncertainty and returning a product. Fraud of this type is significant: such deceptive behavior reportedly accounts for nearly $50 \%$ of all returns in the clothing industry (King et al., 2008). Of the overall U.S. returns in the report on Consumer Returns in the Retail Industry by The Retail Equation (2015), which incorporates data from the U.S. National Retail Federation and the Retail Council of Canada, 3.5\% were considered fraudulent (\$9.12 billion). In Canada, illegitimate (i.e., fraudulent) returns accounted for approximately $4.2 \%$ of the total, or $\$ 1.2$ billion, the report showed.

If not handled efficiently, product returns strain retailers. They decrease net sales, hurt the bottom line, and produce extra costs in the form of managing reverse logistics (e.g., Guide et al., 2006). On a broader level, abuse of RRPs by fraudulent consumers leads to the loss of revenue. To mitigate such losses, retailers increase selling prices for consumers and slash costs by any means, which may also result in the cutting of retail jobs. Adding to this the fact that fraudulent returns lead to the loss of sales taxes to federal and provincial governments, funds which otherwise could have been used for public service, it becomes clear that the impact is societal. Moreover, the environmental damage created in closed loop supply chains due to returns cannot be overlooked (e.g., Rogers and Tibben-Lembke, 2001).

Although there exists an established stream of literature on contract/ return policy design between suppliers and retailers (e.g., Wang et al., 2007), there is much room left for understanding RRPs that exist exclusively between retailers and end consumers. As noted by Ülkü et al. (2013), the optimal design and proper implementation of these RRPs is crucial and requires further investigation.

The developing literature on return policies can be classified as twofold: in the setting of manufacturer-retailer and retailer-consumer. Studies that exclusively examine the return policies between the manufacturer and the retailer focus primarily on contractual designs which outline the terms and conditions for the returned products to the manufacturer by the retailer. Generally, these studies consider the consumer returns rate as an exogenous variable and focus on competition and coordination issues in the supply chain. For example, Xiao et al. (2010) examine the coordination problem in a two-echelon supply chain in which consumer returns and demand are uncertain. They note that both the refund amount and the variation in consumer valuation are instrumental in the design of contracts that coordinate such supply chains. In the presence of product returns from retailers, Li et al. (2012) examine optimal pricing 
and ordering decisions for various channel modes in a dyadic supply chain; and Liu et al. (2014) suggest the existence of a buyback contract that can coordinate a manufacturer-retailer chain when the refund for returns is exogenous to the model. Gümüş et al. (2013) derive conditions for an equilibrium contracting policy for a manufacturer in used goods markets.

Conversely, literature related to the retailer-consumer setting, particularly regarding the aforementioned behavioral issues related to return policies, is gaining attention. Anderson et al. (2009) suggest that RRP has a measurable value for consumers; this value can be quantified, varying across product categories and consumers. Pei et al. (2014) indicate that for an online retailer, leniency in return policies increases consumers' perception of the fairness of the RRPs and purchase intention, whereas Rao et al. (2017) find that leniency in return periods increases product prices and in turn might affect repatronage.

Hess et al. (1996) find support that non-refundable charges can be used to profitably control inappropriate returns. Davis et al. (1998) consider opportunities for retailers to make additional sales when consumers visit a store to return a product. Their study shows that when product benefits cannot be consumed during a short period, when there is an opportunity for cross-selling and when a high salvage value can be obtained for returned merchandise, retailers were more likely to offer a low-hassle RRP. Thang and Tan (2003) report that merchandising, reputation, accessibility, in-store service, and store atmosphere, save post-transaction services, strongly influence consumers' preference of retailer store. Petersen and Kumar (2009 \& 2015) find that to a certain point, people who return moderate amounts of product purchase more in the future; thus, retailers should not merely view RRPs as a cost. Among other reasons, Powers and Jack (2013) report that cognitive dissonance (both emotional and product-related) is strongly related to the frequency of product returns. To reduce consumer product returns, Lee and Yi (2017) suggest that retailers should provide gifts with purchases, whereas Dailey and Ülkü (2018) draw attention to how consumers' return encounters at the service desk may exacerbate retaliation in terms of fraudulent returns. In addition to the complex landscape of consumer return behavior, Ruiz-Benitez and Muriel (2014) point to the fact that managers may tend to ignore consumer returns when making order quantity and price decisions. This brings us to examine how return rates are estimated.

The literature generally reports that product returns increase with the leniency of the RRP (e.g., full refund, return whenever, no questions asked. etc.) and with the quantity sold (Hess et al., 1996; Harris, 2010). Moreover, an increase in fraudulent returns exacerbates the overall product return rate and its related costs to the retailer. In particular, seasonal (e.g., Christmas holiday) product returns are quite problematic (Vlachos and Dekker, 2003; Mostard and Teunter, 2006). Early literature on the estimation of product returns includes Hess and Mayhew (1997), who provide econometric models to estimate the product returns for an apparel marketer. In a different avenue, forecasts for product returns are provided for reusable products returned at the end of their product lives (see, Kelle and Silver, 1989; Toktay et al., 2004). However, with the increased adaptation of online shopping, the issue of returned products is gaining significance. For example, Ofek et al. (2011) suggest that although online channels offer potential benefits to customers who value the convenience of online shopping, these channels also raise new challenges, including higher rates of costly product returns. In a related vein, Foscht et al. (2013) examines the return behavior of mail order shoppers.

A study by Su (2009) is the closest to our study in that it combines both demand and valuation uncertainty in a single-period model. However, our model's emphasis is more on consumer behavior and explicitly differentiates, incorporates and quantifies opportunistic proclivity. Our paper is set apart from the literature above in three ways. We particularly focus on the impact of abused returns on order quantity, provide closed-form optimality solutions for the cases of uniform and exponential demand uncertainties, and explicitly model the differentiated values of
Table 1

Notation.

\begin{tabular}{ll}
\hline$Q$ & Order quantity \\
$P$ & Selling price, in dollars per unit \\
$\bar{P}$ & Consumer reservation price, in dollars per unit \\
$W$ & Wholesale purchase cost, in dollars per unit \\
$H$ & Hassle of returning the product, in dollars per unit \\
$E$ & Unit salvage value of the excess (unsold) inventory, in dollars \\
$S_{\mathrm{A}}$ & Salvage value to the retailer in dollars for a returned abused product \\
$S_{\mathrm{N}}$ & Salvage value to the retailer in dollars for a legitimately returned product \\
$\zeta$ & Expected salvage value to the retailer in dollars for a returned product \\
$\alpha$ & Propensity to abuse the RRP by an opportunistic consumer, $0 \leq \alpha \leq 1$ \\
$\beta$ & Propensity to return a mismatched (malfunctioning) product, $0 \leq \beta \leq 1$ \\
$m$ & Probability that the product has no functional failure during $T$ \\
$T$ & Length of return window (i.e., period), in time units \\
$\theta$ & Sensitivity of the return window to valuation \\
$f(x), F(x)$ & p.d.f. and c.d.f. of the random variable $X$ representing demand \\
$A$ & Probability of an abused return \\
$N$ & Probability of a normal (i.e., legitimate) return \\
$R$ & Probability of a product return, whether abused or not $(R=A+N)$ \\
$K$ & Probability that the consumer keeps the product $(K=1-R)$ \\
$L$ & Service level, i.e., probability of product availability in NVP \\
$c$ & Value consumption rate of the product during $T, 0<c<1$ and $\bar{c}=1-c$ \\
$G$ & Customer's loss of goodwill (in dollars) \\
$s$ & Salvaging rate of the value of the product to the consumer, in dollars \\
$V$, and $v$ & RV denoting consumer's product valuation, and its realized value \\
$\rho$ & Range of effective valuation for the product, in dollars $(\rho=\bar{P}+\theta T-P)$ \\
\hline
\end{tabular}

an excess (unsold) inventory, considering a return due to malfunction (normal or legitimate return) and a product returned after being used by an opportunistic consumer.

In this paper, we aim to shed light on a better understanding of RRPs and consumer return behavior in the setting of inventory management. To that end, as a contribution to the current body of literature, we apply consumers' post-purchase behavior exclusively to the determination of optimal order size for a single-period product (such as fashion goods) with demand uncertainty and vulnerability to opportunistic returns. In so doing, we examine the impact of various pertinent parameters on the returns, particularly opportunistic ones.

\section{Model formulation}

In this section, we set up an analytical model for consumers' postpurchase behavior and the resulting impact on retailers' profit for a single-period product. The model specifics employed are exhibited in Table 1.

We consider a retailer who is selling a particular single-period (perishable) product such as a fashion garment, at the price of $P$ as set by the market, accompanied by a possibly lenient (full refund of the purchase price) return policy (LRP). The LRP may enable the consumer to attempt to use the product during the return window $T$ (e.g., 90 days) and return with a consumer-borne hassle cost of $H$ dollars per unit. In effect, the consumer is partially refunded (cf., Chu et al., 1998). The retailer pays $W$ dollars per unit to the manufacturer. Let $X$ be the random variable representing demand for that product during the selling horizon (e.g., season), and assume $X$ is a continuous random variable with probability density function (p.d.f.) $f(x)$ with mean $\mu$.

Fig. 1 displays our model setting and the relationship between the retailer-product-consumer trilogy. The model integrates retailers' inventory decision-making and consumers' post-purchase behavior, depending on whether the product matches the tastes and expectations of the consumer. In Fig. 1, a square represents a decision node; a circle represents a chance node.

In our model setting, we assume that each consumer arriving at the retail store purchases only one product if it is available. Let us denote by $V$ the random variable representing the consumer's valuation of the product. Let us also denote by $v$ a realization (an observed outcome) of $V$. Suppose that the consumer's intrinsic valuation (reservation price) for the 


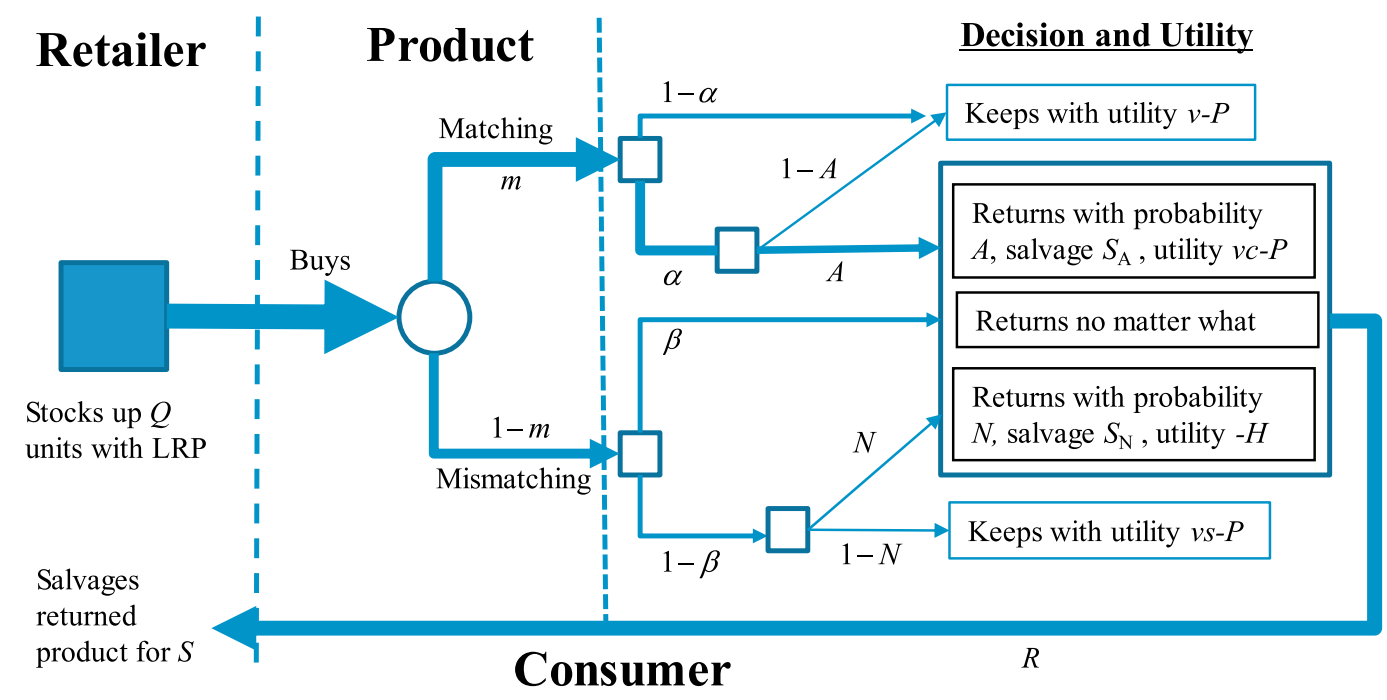

Fig. 1. Consumer post-purchase decision and its impact on retailer inventory.

product is $\bar{P}$ dollars per unit, if no returns were allowed. However, because the return policy provides consumers with flexibility to change their purchasing decision, we assume that the valuation of consumers for the product increases with the length of the return period. Hence, we allow $\bar{P}(T)=\bar{P}+y(T)$, where $y(\bullet)$ is a non-decreasing function of $T$, which could be linear or non-linear. With heterogeneous consumers, we assume $V$ is uniformly distributed over the domain $[P, \bar{P}(T)]$. Then, the valuation range is $\rho=\bar{P}(T)-P$, where $T \geq 0, y(T) \geq 0$, and $P \leq \bar{P}$. We take $y(T)=\theta T$, where $\theta \geq 0$ and denotes the sensitivity of the consumer on the return period of the RRP (cf. Ülkü et al., 2013; Difrancesco et al., 2017).

For various aforementioned reasons, a purchased product may not satisfactorily match with consumer expectations. In this paper, we clearly distinguish between returns that are due to the functional failure of the product and returns that are related to consumer behavior. We denote by $m$ the probability of no functional failure of the product (e.g., the product is not working properly, arrived in damaged condition, etc.) during the return window. We assume that this probability could be estimated through previous returns that are identified as truly defective in function. However, certain returns may not be easily identified as functional failure returns. For example, at the return processing (customer service) center of a retailer, due to high volumes of customers, the true reason for return might be overlooked by service representatives. This type of scrutiny might be more lax particularly if the manufacturer, rather than the retailer, is responsible for return costs and the retailer is only acting as a collection point in the reverse logistics system. Conversely, all other returns may be attributed to "false-failure" returns that are simply due to behavioral issues such as impulsive purchases. The estimation of $m$ for a product could be a challenging task, involving pre- and post-purchase consumer satisfaction surveys. Moreover, in-house records kept for transactions on product returns may provide biased information about mismatch probabilities, because they might not provide information regarding the mismatch property products which are not returned for some reason. For a general idea regarding mismatch rates, an American consumer satisfaction index could be used, wherein results from continuous customer surveys are reported for several sectors. Notably, products differ in their probability of mismatch because they vary regarding fit to consumers' tastes and expectations of product function. For example, garments may have a higher likelihood of mismatch than light bulbs.

If a match occurs, it is natural that most customers keep the product; however, other customers may take the opportunity to return the product after using it during the return period $T$, if returning the product is beneficial to them. We call this type of return an "abused" return.

In an abused return, the consumer may have economic incentive to return the product after using it despite an initial match occurring. We assume that the proportion of customers who tend to abuse the return option is $\alpha$. Abused returns occur if the difference between the refund and the hassle cost is higher than the monetary value of the residual (unconsumed) value of the product, that is, if $P-H>v(1-c)$, such that $0<c \leq 1$, wherecrefers to the consumption proportion of the product during the return period, for a matching product. A higher $c$ value implies a faster or denser consumption (e.g., a prom dress). Therefore, an opportunistic consumer extractsvc of the value of a "matched" product during the return period and then returns it. Whether matched or not, to return the product the consumer pays $H$ dollars of hassle cost (a measure of money spent on gas or transit, time lost, and feelings of disappointment or even anger).

When a mismatch occurs with probability $1-m$, some fraction $\beta$ of consumers return the product no matter what. However, the remaining $1-\beta$ fraction of consumers calculates the utility and returns the product if it is profitable to do so; otherwise, the product is kept for repurposing or simply due to the inability of the consumer to return it. Let $0<s \leq 1$ be a multiplier for the valuation of the consumer of a mismatched product. Then, a consumer receives $v s$ dollars of salvage value if she keeps a mismatched product. Consider, for example, the possibility that a consumer, despite having a legitimate reason to return the product (e.g., due to the wrong color of a clothing item ordered online), may prefer not to return the product but rather to use it as a gift item for Christmas. Conversely, she will return the mismatched product if $P-H>v s$. We term any return of a product when a mismatch occurs as a normal return and a product that is not returned as a kept product. Hence the postpurchase behavior of a customer is described by three options: keep the product or exercise an abused or normal return.

Regarding the retailer's position, we note the following. At the beginning of the season, the retailer has $Q$ units in stock. At the end of the season, any unsold (excess) products and returned products are salvaged at $E$, at an estimate of $S$ dollars, respectively. If a supply shortage occurs, the retailer incurs an underage cost of $G$ dollars per unit. Our foremost objective in this paper is to determine the profit-maximizing order quantity $Q^{*}$ under the scenario in which consumer post-purchase behavior (return or keep) is explicitly integrated. Next, we explain the consumer's decision process.

We quantify the probabilities of the alternative post-purchase actions 
of a customer. Let Nstand for the probability of a normal return. As mentioned above, a mismatched product is returned if $P-H>v$.

Then, recalling that $V$ has a uniform distribution over a range of $\rho$ we can write

$$
\begin{aligned}
N & =(1-m)\left[\beta+(1-\beta) \operatorname{Prob}\left(V<\frac{P-H}{s}\right)\right] \\
& =(1-m)\left[\beta+\frac{(1-\beta)(P-H)}{s \rho}\right] .
\end{aligned}
$$

Note that if $\beta=1$, then $N=1-m$, meaning that all mismatched (malfunctioning) products will be returned.

As discussed above, an abused return occurs if $P-H>V(1-c)$ (notably, without the loss of generality, the values of $c$ and scan be taken independently of each other). A consumer with valuation $v_{\mathrm{O}}=(P-$ $H) / \bar{c}>0$, where $\bar{c}=1-c$, would be indifferent between returning the matched product or not returning the product. To distinguish, we term all consumers whose valuations are less than or equal to that of $v_{0}$, as "opportunistic consumers". Although there may exist economic incentives to do so, because of cultural factors or simply due to their moral compass, not all of the opportunistic consumers would return the product after its use during the return window. To account for this reality, we assume above that a certain fraction $\alpha$ of the consumers may "abuse" the LRP by returning the product once they extract their intended utility from the product. The remaining $1-\alpha$ would keep the product. Therefore, we can cast the probability of an abused return $A$, as

$A=m \alpha \operatorname{Prob}\left(V<\frac{P-H}{(1-c) \rho}\right)=\frac{m \alpha(P-H)}{\bar{c} \rho}$.

It is important to highlight here that the only condition to eliminate abused returns is that the price of the product is less than or equal to the hassle cost of returning it, i.e., $P \leq H$. Considering that an LRP set with such a condition would not be enticing to consumers at all and that this would be an exceptional situation, Eq. (2) reasonably reflects the practice. We also note that in the extreme case of no functional failure (or perfect match), i.e., when $m=1$, we notice from Eq. (1) that there will not be any normal returns $(N=0)$, but there may be a positive amount of abused returns that can be easily verified and quantified as $A_{m=1}=\alpha(P-$ $H) / \bar{c} \rho \geq 0$.

Ultimately, retailers want to sell more products and have satisfied customers who keep and enjoy their products. Let us define by $K$ the probability that a consumer keeps the product, whether matched or mismatched, beyond the return period to use herself or to use for any other reason such as gifting. In other words, $K$ is the probability of the product being kept and is simply the complement of the probability of the product being returned $R$ (the sum of the probability of an abused $\operatorname{return} A$, and the probability of a normal return $N$ ). We then have

$K=1-R$, where $R=A+N$.

Unlike the extant literature, we specifically differentiate between the salvage values of the returned products because this is a salient feature of our model. To that end, we take the retailer's salvage value for an abused return and a normal return as $S_{\mathrm{A}}$, and $S_{\mathrm{N}}$, respectively. We make the plausible assumption that the salvage value of a normal return is at least as large as the salvage value of an abused return, that is, $S_{\mathrm{N}} \geq S_{\mathrm{A}}$. Then, the expected salvage value of "a" returned product $\zeta$ is a probabilistically weighted term, conditioned on the probability of the product being returned $R$, and can be calculated, employing Eq. (1), Eq. (2), and Eq. (3) as

$\zeta=S / R$ where $S=A S_{\mathrm{A}}+N S_{\mathrm{N}}$.

Because returned products involve more costs and possibly damaged quality, we conjecture that for retailers, the salvage value of a product that remained unsold during its season (i.e., excess inventory due to pure demand uncertainty, $E$ ) is plausibly higher than that of its returned counterpart ( $\zeta$ ). We present these relationships as $E>S_{\mathrm{N}} \geq \zeta \geq S_{\mathrm{A}}$. Note that in the formulation of Eq. (4), the expected salvage value of a returned product becomes a function of, among other things, the selling price, the range of the valuation, the hassle cost, and the probability of a match.

Having established all the required definitions and terms, we now turn our attention to developing the retailer's objective function. We build on the well-known newsvendor problem with an implicit assumption that the individual return decision of the consumer is independent of demand distribution, $F$. Of the numerous variations of NVP, one example is when the product is substitutable (Gürler and Y1lmaz, 2010). Recent NVP research, including our study, incorporates behavioral issues into NVP, whether it is the decision-making behavior of the retailer and or the consumer (see Khouja (1999) for an excellent review on NVP).

With this paper, we introduce a new variant of NVP, newsvendor with opportunistic consumers (NVOC), in which consumers may return a product with a hassle cost borne by them, after using the product during the return period. We now define the profit-maximizing objective $\Pi$ of NVOC as follows.

$$
\begin{aligned}
\Pi(Q)= & -W Q+\int_{0}^{Q}[P K x+E(Q-x)+S x] d F(x)+\int_{Q}^{\infty}[P K Q+S Q \\
& -G(x-Q)] d F(x)
\end{aligned}
$$

The objective function in Eq. (5) includes the following five cost and revenue components:

i) The cost of purchasing $Q$ units from the supplier, $W Q$.

ii) The expected revenue (net returns from the total sales $x$ ), that is, $\int_{0}^{Q} P K x d F(x)$, if $x<Q$ and $\int_{Q}^{\infty} P K Q d F(x)$, if $x \geq Q$.

iii) The expected salvage value for the unsold (excluding returns) inventory, $\int_{0}^{Q} E(Q-x) d F(x)$.

iv) The expected salvage value from the returns, whether abused or normal, $\int_{0}^{Q} \zeta R x d F(x)=\int_{0}^{Q} S x d F(x)$ if $x<Q$, and $\int_{Q}^{\infty} S Q d F(x)$ if $x \geq Q$.

v) The cost of loss of goodwill that occurs when demand is unmet due to stock shortage, $\int_{Q}^{\infty} G(x-Q) d F(x)$ when $x \geq Q$.

In the next section, we provide optimal solutions to NVOC, provide structural results, and benchmark the optimal solution of NVOC to profitmaximizing NVP.

\section{Optimal solutions and structural results}

In this section, we first provide the optimal solutions and structural results in terms of propositions and lemmas. At the end, we provide a discussion of these results and their relation to management.

Let the optimal order quantity for NVOC be $Q^{*}$ and the corresponding optimal expected profit be $\Pi^{*}$.

Theorem 1. Let $u=P K+S+G-W$ be the underage cost for NVOC, $o=$ $W-E$ be the overage cost, $L=u /(u+o)$ be the service level, and $Z(t)=$ $\int_{0}^{t} x d F(x)$. There exists a unique maximizer of $\Pi(Q)$, and the unique optimal order quantity and the optimal expected profit are given by

$Q^{*}=F^{-1}\left(\frac{u}{u+o}\right)=F^{-1}(L)=F^{-1}\left(\frac{P K+S+G-W}{P K+S+G-W}\right)$,

$\Pi^{*}=\Pi\left(Q^{*}\right)=u Q^{*}-G \mu-(u+o)\left[Q^{*} F\left(Q^{*}\right)-Z\left(Q^{*}\right)\right]$.

Proof. Expanding Eq. (5) and substituting for $F(Q)=\int_{0}^{Q} d F, F(Q)+$ $\int_{0}^{Q} d F=1, Z(Q)=\int_{0}^{Q} x d F, \mu=\int_{0}^{\infty} x d F$ we obtain 


$$
\begin{aligned}
\Pi(Q)= & P K \int_{0}^{Q} x d F+E Q \int_{0}^{Q} x d F+(S-E) \int_{0}^{Q} x d F-W Q\left[\int_{0}^{Q} d F+\int_{Q}^{\infty} d F\right] \\
& +[P K Q+S Q+G Q] \int_{Q}^{\infty} d F-G \int_{Q}^{\infty} x d F \\
= & {[P K+E Q+S-E] Z(Q)+[P K Q+S Q+G Q][1-F(Q)] } \\
= & {[P K+S[\mu-Z(Q)]-W Q} \\
\quad &
\end{aligned}
$$

We rewrite the expected profit function as

$\Pi(Q)=u Q-G \mu-(u+o)[Q F(Q)-Z(Q)]$

To find the optimal order quantity, we investigate the first order condition. To begin, note that via Leibniz's rule, we find $Z^{\prime}(Q)=d Z(Q) / d Q=$ $Q f(Q) \geq 0$ because by our model setting, $Q \geq 0$. Then, we find the explicit expression for the first derivative of $\Pi(Q)$ in Eq. (8) and its sign as follows: $\Pi^{\prime}(Q)=d \Pi(Q) / d Q=u-(u+o) F(Q)$. Solving for $Q$, the optimal order quantity is obtained as $Q^{*}=\left\{Q: \Pi^{\prime}(Q)=0\right\}=F^{-1}[u /(u+o)]=F^{-1}(L)$.

The uniqueness of the optimal solution can be checked via second order condition: $\Pi^{\prime \prime}(Q)=d^{2} \Pi(Q) / d Q^{2}=d \Pi^{\prime}(Q) / d Q=-(u+$ o) $f(Q)<0$. $\Pi^{\prime \prime}(Q)<0$ implies that $\Pi(Q)$ is concave everywhere and thus $Q^{*}$ is the unique maximizer. This is the result obtained in Eq. (5). Finally, inserting $Q=Q^{*}$ in Eq. (8) and denoting the optimal expected profit $\Pi^{*} \equiv \Pi\left(Q^{*}\right)$, we obtain the expression in Eq. (7). This completes the proof.

Next, we consider the behavior of the abused return probability, the optimal order quantity and the optimal expected profit with respect to price $P$, return window $T$, abused return probability $A$ and salvage value $S$ for a returned product. To this end, we first provide a simple result as follows, which is obtained by straightforward algebra.

Lemma 1. Consider a function of the form, $w(x)=\frac{i x+a}{j x+b}$. Then, $w(x)$ is increasing (decreasing) in $x$ if ib $>(<) j a$.

Proposition 1. The service level $L$ is: $i$ ) increasing in price $P$; ii) decreasing in abused return probability $A$; iii) increasing in return window $T$, and iv) decreasing in expected salvage value $S$.

Proof. We have $L=\frac{u}{u+0}=\frac{P K+S+G-W}{P K+S+G-E}$. We invoke Lemma 1 for all parts. As an example, for part i) we have $i=j=K, a=S+G-W$, and $b=S+$ $G-E$. We have $b>a$, because $W>E$. The other parts follow similarly. For part ii), note that $S=A S_{\mathrm{A}}+N S_{\mathrm{N}}$ and Lemma 1 applies.

Proposition 2. The retailer's optimal order quantity $\left.Q^{*} i s: i\right)$ increasing in price $P$; ii) decreasing in abused return probability $A$; iii) increasing in the return window $T$, and iv) decreasing in expected salvage value $S$.

Proof. Recall that $Q^{*}=F^{-1}(L)=F^{-1}\left(\frac{P K+S+G-W}{P K+S+G-E}\right)$. For part i), we have $\frac{d Q^{*}}{d P}=\frac{d F^{-1}(L)}{d L} \cdot \frac{d L}{d P}>0$. Here, we use the fact that since $X$ is a continuous random variable, both $F$ and $F^{-1}$ are increasing in their arguments. Hence, the first term in the above product is positive, and so is the second term by Lemma 2 . The other parts follow similarly.

Proposition 3. The retailer's optimal profit $\Pi^{*}$ is: i) increasing in price $P$; ii) decreasing in probability of abused returns $A$; iii) increasing in return window $T$, and iv) decreasing in $S$.

Proof. Substituting the optimal order quantity given in Eq. (6) into Eq. (7), we obtain

$\Pi^{*}=\Pi\left(Q^{*}\right)=(u+o) Z\left(Q^{*}\right)-G \mu$. We also have $u+o=P K+S+G-$ $E$. For part i), we then have $\frac{d \Pi\left(Q^{*}\right)}{d P}=K Z\left(Q^{*}\right)+P K \frac{d Z\left(Q^{*}\right)}{d P}=K Z\left(Q^{*}\right)+$ $P K \frac{d Z\left(Q^{*}\right)}{d Q^{*}} \frac{d Q^{*}}{d P}>0$, which follows because the first term is positive by definition and the second one by Proposition 2 and the fact that $\frac{d Z\left(Q^{*}\right)}{d Q^{*}}=$ $Q^{*} f\left(Q^{*}\right)>0$. The other parts follow similarly.

The analytical results stated above indicate intuitively expected relations in terms of price and abused return probability. Increased optimal order quantity and expected profit with return window $T$, however, may not be as obvious; allowing a longer return period results in an increase of both order quantity and the resulting expected profit. We may explain this result by the fact that as the return period increases, the utility for the customer increases, which results in reduced return probabilities.

The result that both the optimal order quantity and the optimal expected profit decrease in $S$, the salvage value of the returned product, also may seem counterintuitive at first sight; however, this finding makes sense because when salvage for abused and legitimate returns are fixed, $S$ will increase when returns are increased (abused or normal), which will result in a decrease in $L$.

\section{Closed-form optimal solutions and numeric examples}

In this section, we develop closed-form solutions for the case of uniform demand and exponential demand distributions. Exponential demand distribution, with a coefficient of variation 1 , is suitable for products with highly uncertain demand, such as fashion goods (see Lau, 1997).

Proposition 4. If demand $(X)$ for a single-period, returnable product is uniformly distributed over $[a, b]$, the retailer's optimal NVOC order quantity $Q_{\text {Unif }}^{*}$ and the corresponding maximum profit $\Pi_{\text {Unif }}^{*}$ follow:

$Q_{U n i f}^{*}=a+(b-a) L$, and $\Pi_{U n i f}^{*}=[2 u a-G(a+b)+(b-a) u L] / 2$

Proof. $\quad X \sim$ Uniform $[a, b]$ implies that $F(x)=(x-a) /(b-a)$. From Eq. (6), we obtain $F\left(Q_{\text {Unif }}^{*}\right)=\left(Q_{U n i f}^{*}-a\right) /(b-a)=L$ and therefore $Q_{U n i f}^{*}=$ $a+(b-a) L$. Then, $Q_{U n i f}^{*} F\left(Q_{U n i f}^{*}\right)=a L+(b-a) L^{2}$ and by definition $Z\left(Q_{U n i f}^{*}\right)=\int_{a}^{Q_{U n i f}^{*}}[x /(b-a)] d x=\left(Q_{U n i f}^{* 2}-a^{2}\right) / 2(b-a)$. Plugging in $Q^{*}$ from above and simplifying, we obtain $Z\left(Q_{\text {Unif }}^{*}\right)=a L+(b-a) L^{2} / 2$. Using algebra, we then obtain $Q_{U n i f}^{*} F\left(Q_{U n i f}^{*}\right)-Z\left(Q_{U n i f}^{*}\right)=(b-a) L^{2} / 2$. Finally, from Theorem 1, plugging the above terms in Eq. (8) combined with the fact that $\mu_{\text {Unif }}=(a+b) / 2$, we obtain the closed form optimal profit function $\Pi_{\text {Unif }}^{*}$ as shown in Proposition 4 above.

Proposition 5. If demand $(X)$ for a single-period, returnable product is exponentially distributed with rate $\lambda$, the retailer's profit-maximizing order quantity $Q_{E x p o}^{*}$ and the corresponding optimal profit $\Pi_{E x p o}^{*}$ are:

$Q_{\text {Expo }}^{*}=|\ln (1-L)| \lambda^{-1}$, and
$\Pi_{E x p o}^{*}=u Q_{E x p o}^{*}-G \lambda^{-1}-(u+o)\left[Q_{E x p o}^{*}-\left(1-e^{-\lambda Q_{E x p o}^{*}} \lambda^{-1}\right)\right]$,

where $|\bullet|$ returns the positive value of the argument.

Proof. $\quad X^{\sim}$ Exponential $(\lambda)$, then $\mu_{\text {Expo }}=\lambda^{-1}$. By definition, $f(x)=$ $\lambda e^{-\lambda x}$ if $x \geq 0$; 0 , otherwise. Additionally, $F(x)=1-e^{-\lambda x}$ if $x \geq 0$; 0 , otherwiseFrom Proposition 1, we obtain $Z\left(Q_{\text {Expo }}^{*}\right)=\mu_{\text {Expo }}[1-(1+$ $\left.\lambda Q_{E x p o}^{*}\right) e^{-\lambda Q_{E x p o}^{*}}$. Similar to the steps followed in the proof of Proposition 4, by substituting these terms in Eq. (6) and using algebra, we derive the closed-form formulae in Eq. (10).

To illustrate the mechanics and the utility of the model in Eq. (10), we employ for our numerical examples the following hypothetical "base case" parameter values shown in Table 2 . One should exercise caution that, unlike our generalized structural results in preceding sections, the insights revealed from these examples confine to the case when the market demand is exponentially distributed.

These values may reflect, for example, a sweater that sells on average 100 units in the winter season, retailing at $\$ 42$ with an allowed return period of 30 days. Using Eqs. (1) and (2), we find that the rate for abused returns and normal returns are $25.4 \%$ and $37 \%$, respectively. Then, from Eq. (4), the expected salvage value of a returned product $\varsigma$ is computed as 
Table 2

Base case parameters for numeric example.

\begin{tabular}{|c|c|c|c|c|c|c|c|c|c|c|c|c|c|c|c|}
\hline Parameter & $\mu$ & $P$ & $T$ & $m$ & $c$ & $s$ & $\alpha$ & $\beta$ & $\theta$ & $E$ & $G$ & $H$ & $W$ & $S_{\mathrm{A}}$ & $S_{\mathrm{N}}$ \\
\hline Value & 100 & 42 & 30 & 0.8 & 0.6 & 0.1 & 0.5 & 0.9 & 0.5 & 10 & 5 & 15 & 12 & 5 & 8 \\
\hline
\end{tabular}
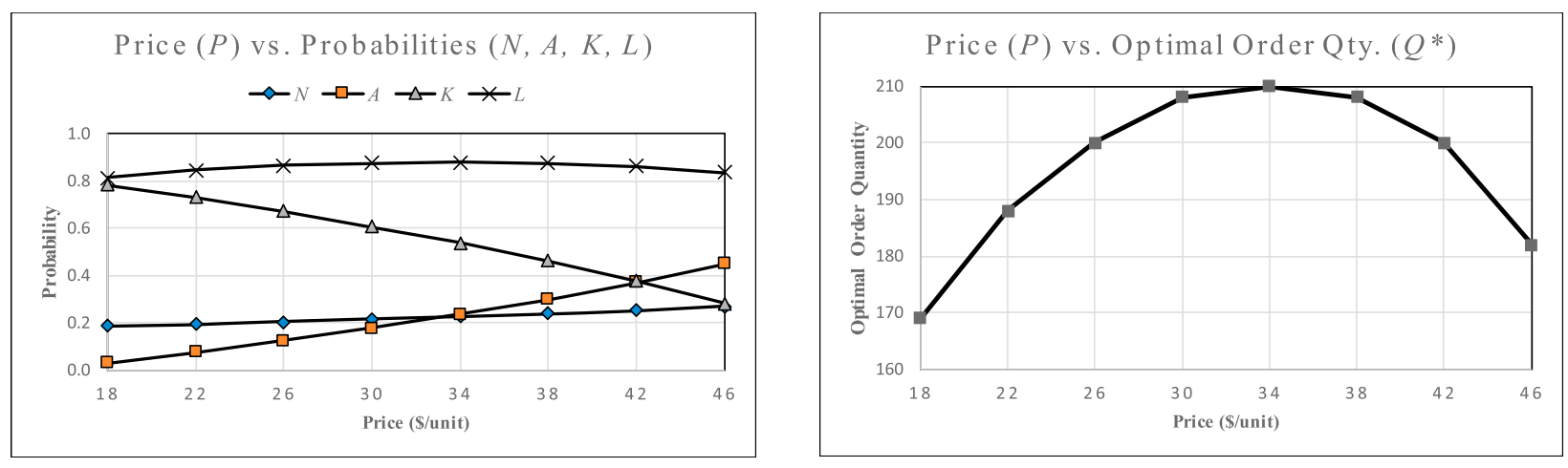

Price $(P)$ vs. Expected Salvage Value of Returned Product $(\varsigma)$
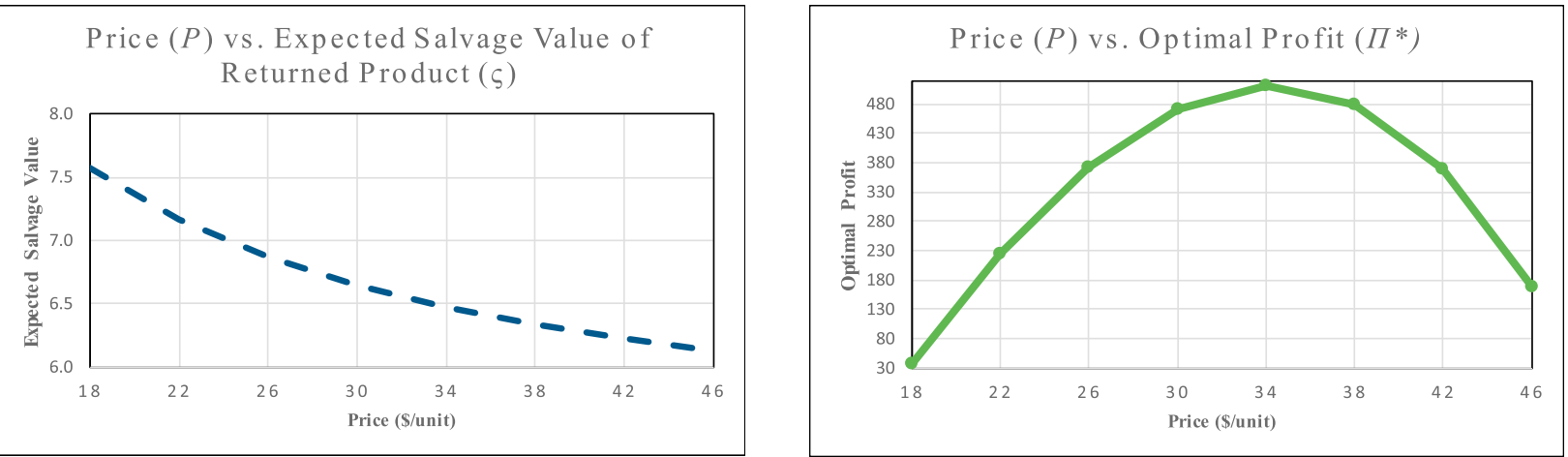

Fig. 2. Sensitivity to changes in price.
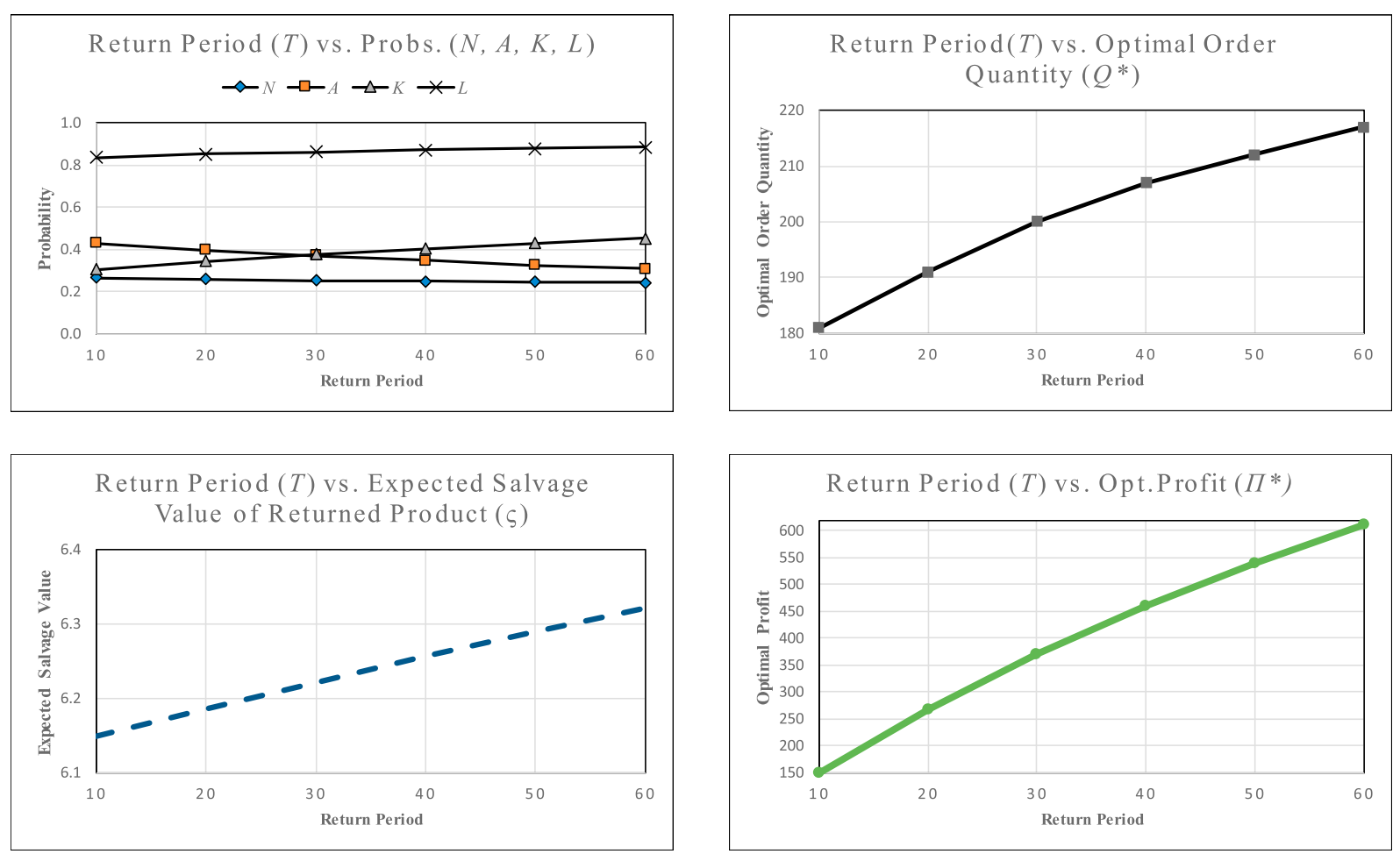

Fig. 3. Sensitivity to changes in return period. 

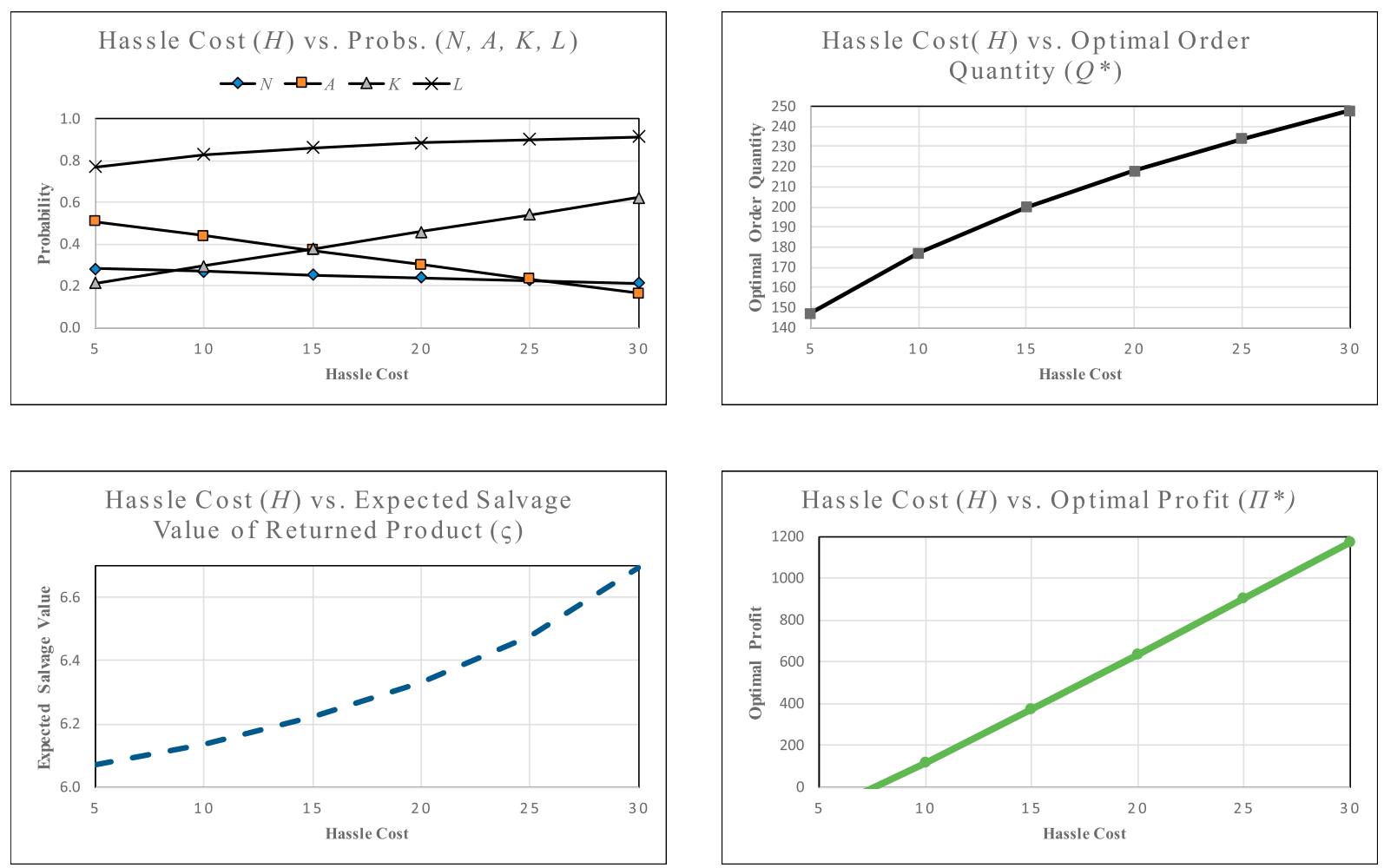

Fig. 4. Sensitivity to changes in hassle cost borne by the consumer.

$\$ 6.20$ per unit returned. Finally, via Eq. (10), we find $Q^{*}=200$ and $\Pi$ $\left(Q^{*}\right)=\$ 369.3$. We now turn our attention to sensitivity analyses, in which we examine the behavior of the performance measures of our model as we change key parameters one at a time. We identify the most important parameters salient to our model as price $(P)$, return window $(T)$, and hassle cost $(H)$. We chart the impacts of these parameters one by one on i) the probability of a normal return $(N)$; ii) the probability of an abused return $(A)$; iii) the probability that the product will be kept $(K)$; iv) the service level $(L)$; v) the expected salvage value of a returned product (ऽ); vi) optimal order quantity $\left(Q^{*}\right)$; and vii) the corresponding optimal profit $\left(\Pi^{*}\right)$.

We notice from Fig. 2 that as the selling price of the product increases, both the probability of a normal and an abused return increases, with the latter showing a relatively steeper slope. Conversely, the cumulative effect of these returns results in a declining probability of keeping the product; in other words, as the price increases, returns will increase either because there is a higher risk for keeping a mismatched product (in monetary terms) and/or because the pool of potential consumers will decrease due to the increased price. As the return rate increases, the expected salvage value decreases in price. The resultant service level (i.e., the probability that a consumer will find the product available on the shelf upon arrival at the store) is nearly flat at approximately $80 \%$. The optimal order quantity and profit are both concave in price. Therefore, price could also be taken as a decision variable (this observation constitutes one of the future extensions of this research).

According to Fig. 3, as the return period increases (i.e., the return policy becomes more lenient), surprisingly we find that the rates decrease for both normal and abused returns, resulting in an increased number of product kept and an increased average salvage value. The overall impact of increasing the return period is also reflected in increased order size and enhanced profit. The positive impact of leniency in return period may be due to enhanced sales, as reflected in a larger valuation range $\rho$ due to an increase in $T$, which also by our modeling convention decreases the likelihood of returns. For example, as consumers keep the product for a longer period, the value extracted increases. Unless a customer is deliberately inclined to return a product by fraudulent proclivity, a return becomes more of a hassle as the cost is borne by the consumer himself/ herself. In short, in the scope of this numerical example, increasing the return period enhances profitability.

Fig. 4 shows the impact of hassle cost on various model performances. Similar to the impacts of price and return period, the return rates (normal and abused) are decreasing in hassle cost. However, we also notice that service level, unlike price and return period, is strictly increasing in $H$. A decrease in returns reflects increasing expected salvage value. Higher hassle costs also imply higher order quantity and profits at optimality. Because our model exclusively examines the post-purchase behavior of consumers rather than the pre-purchase behavior, that modeling asymmetry is reflected here; if the consumer had included hassle cost in her purchasing decision, this result might have been different (again, this observation leads us to a new extension for our model in which we jointly model pre-purchase and post-purchase decisions). Regarding profitability, our computations suggest that $\$ 7.65$ is the breakeven hassle cost, below which the retailer faces a loss. Finally, a higher hassle cost may nullify the incentive for the consumer to return a product fraudulently. This raises the issue for retailers to determine the amount of the hassle cost in such a way that while demand is preserved, fraudulent proclivity is minimized (cf., Davis et al., 1998). This issue is not uncommon for certain online retailers; if the return policy is read carefully, consumers might realize that the cost of returning the product is sometimes higher than the cost of the product itself. One way to increase the hassle of returning products is to impose more stringent conditions of return. Such conditions include requiring the purchase receipt, keeping the package of the product unopened, or returning the product to a service facility instead of the store where it was bought.

From the graphs above, we note that the expected salvage value is increasing in return period and in hassle cost but decreasing in price. The ability to contain the cost of returned products is an important determinant in managing costs, and a trade-off between return period and 

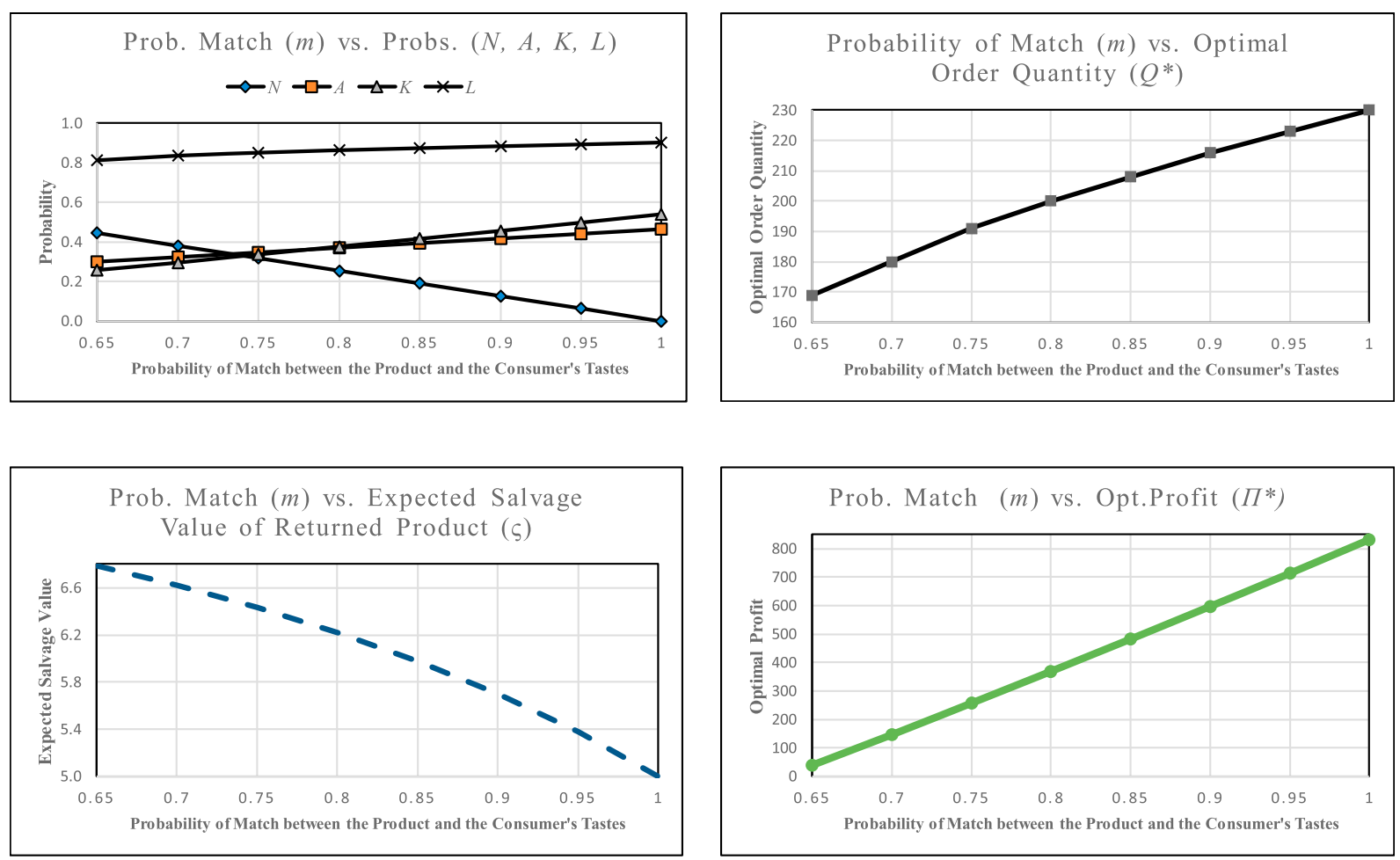

Fig. 5. Sensitivity to changes in the probability of match between product and consumer.

hassle cost must be well-analyzed. Simply reducing hassle cost and allowing a longer return period (i.e., LRP) does not necessarily guarantee enhanced profitability. Therefore, retailing policy makers should investigate mechanisms that minimize the risk of damage to the returned product. For example, this may be achieved to a certain extent by requiring purchasers to use a special package for returning products. Another approach in keeping the salvage value as high as possible lies in the design of the RRP. For products whose utility can be fully used by consumers (e.g., prom dresses), the return period may be set for a shorter period of time. Again, caution must be exercised regarding the trade-off between the risk of losing the consumer to competition because of a strict RRP and increasing the chances of product abuse with a lenient RRP (cf., Xu et al., 2015; Rao et al., 2017).

In a dyadic supply chain setting, manufacturers and retailers may have different salvage capabilities. For example, manufacturers may liquidate the returned product via an off-price retailer, whereas retailers may utilize price markdowns (e.g., Tsay, 2001; Crocker and Letizia, 2014). Those salvage capabilities may be dictated by market dynamics and may be quantifiable. However, in the consumer-retailer domain, it may be difficult for a retailer to truly distinguish the salvage value difference between a legitimate and an abused return. Although our modeling arguably assumes that, due to its intentional elongated use, a fraudulently returned product has lesser value than that of a legitimate one, data analytics may be employed to better forecast and assess such values if a returns management system with data analytics is employed. Additionally, at the returns service encounter, after checking the condition of the returned product, the staff may put a more precise salvage evaluation on it. Because the salvage values $S_{\mathrm{A}}$ and $S_{\mathrm{N}}$ are exogenous to our model, they can be easily calibrated with respect to the available data of a retailer (c.f. Kandel, 1996).

How does match probability affect the decisions in NVOC? Fig. 5 depicts the pertinent sensitivity analyses. As the product matching (i.e., no functional failure) probability increases, the service level (i.e., product availability) at the retailer's stocking point increases, as does the probability that consumers will keep the product. However, while the rate of returns for legitimate reasons (normal returns) decreases inm, the rate of abused returns increases inm. Considering the behavior of an opportunistic consumer, this result makes sense because such an opportunistic consumer would like to extract value from a product that is wellfunctioning during the return window, as opposed to a malfunctioning one. That is, higher quality products might be more appealing to opportunistic returners. Nevertheless, we also observe from Fig. 5 that an increase in mresults in a decrease in the expected salvage value of the returned product and an increase in the optimal order quantity and the profit. Notably, for this particular set of parameters in the sensitivity analysis, if $m \leq 0.62$ there is no profit; instead, there is a loss for the retailer. This example also highlights the importance of considering the "big picture" of the logistics of the product reaching the hands of the consumer. A product that is shipped from the manufacturer or distribution center may be in perfect condition, but if it is damaged during transportation to the consumer's location (as in e-tailing), the functionality of the product would be reduced, resulting in a smaller value of $m$, which in turn would hurt the retailer's bottom line and increase logistical and environmental costs due to increased returns.

\section{Concluding remarks}

Returns management and implementation are becoming increasingly challenging, and the resulting costs of returns are sizable. Of concern is the exacerbating fact that fraudulent proclivity and abused returns exist, and they always will. Although return policies may be revenue drivers, it is critical for retailers to be vigilant in deploying mechanisms that will mitigate the risk of such returns. Indeed, the recent advent of technology and big data pave the way for additional insights into how predictions about consumer behavior can be better utilized within modern retailing operations.

As part of the path to understanding the intricacies between consumer return behavior and inventory management, this paper proposed a variation of the classical newsvendor model, newsvendor with opportunistic consumers, that explicitly integrated consumers' post-purchase decisions. The versatility of our modeling enabled us to differentiate between the failure returns and the false-failure returns, explicitly 
differentiating the salvage values of the returned products. We also provided closed form solutions for demand market uncertainty under which demand could be uniformly or exponentially distributed. Because demand uncertainty is better reflected in exponential demand (a higher coefficient of variation), we conducted numerical and sensitivity analysis for this case. Our formal model exclusively optimized the expected profitmaximizing ordering amount. The resulting model could be employed by retailing decision-makers, particularly in situations in which product price and its associated RRP are set by competition, when all that remains for retailers is the efficient inventory control of a product.

As with any study, certain limitations require us to use caution when interpreting our results. Although we provide general structural results in Section 4, this study would further benefit from validation of the values applied to the parameters used in the numeric example, which could be industry specific. Second, instead of a static return probability function, a dynamic function linked to the length of the return window may provide additional managerial insights. This variation offers a potential research avenue to be explored, examining how the probability of abused returns varies over time.

In addition, there is room for further study concerning general consumer behavior and inventory management/control. For example, in what different ways is omni-channel retailing, as opposed to pure brickand-mortar or pure e-tailing, affected by renting consumers? How can an integrated returns management system be developed so that the risks of abusing RRP are minimized, while flexibility and leniency in returns provide improved customer service? Another research extension would be to study the cascading effect of consumers' return behavior on the triad of consumer, retailer (customer), and manufacturer (vendor) in a supply chain. Overall, the joint optimization of pricing (and hassle cost), return period, and order quantity in NVOC remains a modeling challenge, which we plan to study next. Finally, understanding the impact of fraudulent proclivity on sustainable operations (cf. Ülkü and Hsuan, 2017) in the retailing system offers an intriguing area of research, particularly in the setting of this paper in which the salvage values of returned products are differentiated.

\section{Acknowledgments}

The authors are grateful to Dr. Peter Kelle, IJPE Editor-North America, and anonymous referees for their valuable comments and suggestions on the earlier versions of this paper.

\section{References}

Anderson, E.T., Hansen, K., Simester, D., 2009. The option value of returns: theory and empirical evidence. Market. Sci. 28 (3), 405-423.

Appriss Retail, 2017. Consumer Returns in the Retail Industry (accessed on December 10, 2017) [available online at: https://appriss.com/retail/wp-content/uploads/sites/ 4/./12/2017 Consumer-Returns-in-the-Retail-Industry-Report.pdf].

Chu, W., Gerstner, E., Hess, J.D., 1998. Managing dissatisfaction: how to decrease customer opportunism by partial refunds. J. Serv. Res. 1 (2), 140-155.

Crocker, K.J., Letizia, P., 2014. Optimal policies for recovering the value of consumer returns. Prod. Oper. Manag. 23 (10), 1667-1680.

Dailey, L.C., Ülkü, M.A., 2018. Retailers beware: on denied product returns and consumer behavior. J. Bus. Res. 86, 202-209.

Davis, S., Hagerty, M., Gerstner, E., 1998. Return policies and the optimal level of "hassle." J. Econ. Bus. 50 (5), 445-460.

Difrancesco, R.M., Huchzemeier, A., Schröder, D., 2018. Optimizing the return window for online fashion retailers with closed-loop refurbishment. Omega: Int. J. Manag. Sci. 78, 205-221.

Ferguson, M., Guide Jr., V.D.R., Souza, G.C., 2006. Supply chain coordination for false failure returns. Manuf. Serv. Oper. Manag. 8 (4), 376-393.

Foscht, T., Ernstreiter, K., Maloles, C., Sinha, I., Swoboda, B., 2013. Retaining or returning?:Some insights for a better understanding of return behaviour. Int. J. Retail Distrib. Manag. 41 (2), 113-134.

Guide Jr., V.D.R., Souza, G.C., Van Wassenhove, L.N., Blackburn, J.D., 2006. Time value of commercial product returns. Manag. Sci. 52 (8), 1200-1214.

Gümüs, M., Ray, S., Yin, S., 2013. Returns policies between channel partners for durable products. Market. Sci. 32 (4), 622-643.

Gürler, Ü., Yılmaz, A., 2010. Inventory and coordination issues with two substitutable products. Appl. Math. Model. 34 (3), 539-551.
Harris, L.C., 2008. Fraudulent return proclivity: an empirical analysis. J. Retailing 84 (4), 461-476.

Harris, L.C., 2010. Fraudulent consumer returns: exploiting retailers' return policies. Eur. J. Market. 44 (6), 730-747.

Hess, J.D., Chu, W., Gerstner, E., 1996. Controlling product returns in direct marketing. Market. Lett. 7 (4), 307-317.

Hess, J., Mayhew, G.E., 1997. Modeling merchandise returns in direct marketing. J. Direct Mark. 11 (Spring), 20-35.

Hjort, K., Lantz, B., 2012. (R) e-tail borrowing of party dresses: an experimental study. Int. J. Retail Distrib. Manag. 40 (12), 997-1012.

Hsu, T., 2018. L.L. Bean, Citing Abuse, Tightens its Generous Policy on Returns. Available at: https://www.nytimes.com/2018/02/09/business/1l-bean-returns-policy.html.

Kandel, E., 1996. The right to return. J. Law Econ. 39 (1), 329-356.

Kelle, P., Silver, E.A., 1989. Forecasting the returns of reusable containers. J. Oper. Manag. 8 (1), 17-35.

Ketzenberg, M.E., Zuidwijk, R.A., 2009. Optimal pricing, ordering, and return policies for consumer goods. Prod. Oper. Manag. 18 (3), 344-360.

Khouja, M., 1999. The single-period (news-vendor) problem: literature review and suggestions for future research. Omega 27 (5), 537-553.

King, T., Dennis, C., 2003. Interviews of deshopping behaviour: an analysis of theory of planned behaviour. Int. J. Retail Distrib. Manag. 31 (3), 153-163.

King, T., Dennis, C., Wright, L.T., 2008. Myopia, customer returns and the theory of planned behavior. J. Market. Manag. 24 (1/2), 185-203.

Lau, H.S., 1997. Simple formulas for the expected costs in the newsboy problem: an educational note. Eur. J. Oper. Res. 100 (3), 557-561.

Lee, S., Yi, Y., 2017. Seize the deal, or return it regretting the gift you lost: the effect of gift-with-purchase promotions on product return intentions. Psychol. Market. 34 (3), 249-263.

Li, Y., Wei, C., Cai, X., 2012. Optimal pricing and order policies with B2B product returns for fashion products. Int. J. Prod. Econ. 135 (2), 637-646.

Li, Y., Xu, L., Choi, T.M., Govindan, K., 2014. Optimal advance-selling strategy for fashionable products with opportunistic consumers returns. IEEE Transactions on Systems, Man, and Cybernetics: Systems 44 (7), 938-952.

Liu, J., Mantin, B., Wang, H., 2014. Supply chain coordination with customer returns and refund-dependent demand. Int. J. Prod. Econ. 148, 81-89.

Mostard, J., Teunter, R., 2006. The newsboy problem with resalable returns: a single period model and case study. Eur. J. Oper. Res. 169 (1), 81-96.

Ofek, E., Katona, Z., Sarvary, M., 2011. "Bricks and Clicks": the impact of product returns on the strategies of multichannel retailers. Market. Sci. 30 (1), 42-60.

Pei, Z., Paswan, A., Yan, R., 2014. E-tailer's return policy, consumer's perception of return policy fairness and purchase intention. J. Retailing Consum. Serv. 21 (3), 249-257.

Petersen, J.A., Kumar, V., 2009. Are product returns a necessary evil? Antecedents and consequences. J. Market. 73 (3), 35-51.

Petersen, J.A., Kumar, V., 2015. Perceived risk, product returns, and optimal resource allocation: evidence from a field experiment. J. Market. Res. 52 (2), 268-285.

Powers, T.L., Jack, E.P., 2013. The influence of cognitive dissonance on retail product returns. Psychol. Market. 30 (8), 724-735.

Rao, S., Lee, K.B., Connely, B., Iyengar, D., 2017. Return time leniency in online retail: a signaling theory perspective on buying outcomes. Decis. Sci. J. 49 (2), 275-305.

Rogers, D.S., Tibben-Lembke, R., 2001. An examination of reverse logistics practices. J. Bus. Logist. 22 (2), 129-148.

Ruiz-Benitez, R., Muriel, A., 2014. Consumer returns in a decentralized supply chain. Int. J. Prod. Econ. 147, 573-592.

Shang, G., Ghosh, B.P., Galbreth, M.R., 2017. Optimal retail return policies with wardrobing. Prod. Oper. Manag. 26 (7), 1315-1332.

Su, X., 2009. Consumer returns policies and supply chain performance. Manuf. Serv. Oper. Manag. 11 (4), 595-612.

Thang, D.C.L., Tan, B.L.B., 2003. Linking consumer perception to preference of retail stores: an empirical assessment of the multi-attributes of store image. J. Retailing Consum. Serv. 10 (4), 193-200.

The Retail Equation, 2015. Consumer Returns in the Retail Industry. https://www. theretailequation.com/retailers/industryreports (accessed on September 1, 2017).

Toktay, L.B., van der Laan, E.A., de Brito, M.P., 2004. Managing product returns: the role of forecasting. In: Reverse Logistics. Springer, Berlin, Heidelberg, pp. 45-64.

Tsay, A.A., 2001. Managing retail channel overstock: markdown money and return policies. J. Retailing 77 (4), 457-492.

Ülkü, M.A., Dailey, L.C., Yayla-Küllü, H.M., 2013. Serving fraudulent consumers? The impact of return policies on retailer's profitability. Serv. Sci. 5 (4), 296-309.

Ülkü, M.A., Hsuan, J., 2017. Towards sustainable consumption and production: competitive pricing of modular products for green consumers. J. Clean. Prod. 142, 4230-4242.

Vlachos, D., Dekker, R., 2003. Return handling options and order quantities for single period products. Eur. J. Oper. Res. 151 (1), 38-52.

Wang, H., Wang, W., Kobaccy, K.A.H., 2007. Analysis and design of returns policies from a supplier's perspective. J. Oper. Res. Soc. 58 (3), 391-401.

Wood, S.L., 2001. Remote purchase environments: the influence of return policy leniency on two-stage decision processes. J. Market. Res. 38 (2), 157-169.

Xiao, T., Shi, K., Yang, D., 2010. Coordination of a supply chain with consumer return under demand uncertainty. Int. J. Prod. Econ. 124 (1), 171-180.

Xu, L., Li, Y., Govindan, K., Xu, X., 2015. Consumer returns policies with endogenous deadline and supply chain coordination. Eur. J. Oper. Res. 242 (1), 88-99. 